\title{
Influence of Process Parameters of Friction Stir Welding (FSW) on the Mechanical Properties and the Surface Quality of Welded Joint
}

\author{
Abeer S. Eisa and Osama M. Mabrouk \\ ${ }^{1}$ Department of Production Engineering \& Mech. Design. Faculty of Eng., Menoufia University \\ (Corresponding author: Drabeereisa78@yahoo.com)
}

\begin{abstract}
In this work, the independently controllable parameters, which have a large influence on the surface quality of Aluminum alloy 6082-T61 welded joints when using (FSW) and (CFSW), are studied and analyzed. These parameters are; rotational speed (600-1200 rpm), welding speed (80-160 mm / min), and amplitude (40-100 $\mu \mathrm{m})$. The results for the (FSW) and the (CFSW) methods show that the ultimate tensile strength at low and medium welding speeds ( 80 and $120 \mathrm{~mm} / \mathrm{min}$ ) is generally high in both two methods of welding, and it is increased by about $16 \%$ in UAFSW than the conventionally (CFSW). The elongation is increased when ultrasonic vibration is applied and the percentage of increases are 15 and $7 \%$ is obtained at welding speeds of 80 and $120 \mathrm{~mm} / \mathrm{min}$ respectively. The increase of the welding speed to $160 \mathrm{~mm} / \mathrm{min}$, leads to the obvious increase in the surface roughness $(\mathrm{Ra})$. ( $\mathrm{Ra}$ ) values are high at the beginning of the welding span for all use of the rotational and the welding speeds. But in the middle distance of span, the improvement of the surface quality is clear, and at the end of the welding operation, the values of $(\mathrm{Ra})$ is increased but with small values of roughness as compared with the values at the beginning of welding operation. The rotational speed of the tool is the important factor that has a large influence on the resultant surface roughness ( $\mathrm{Ra}$ ) of the welded area and the increase in tool rotary speed decreases the surface roughness $(\mathrm{Ra})$.
\end{abstract}

Keywords: friction stir welding; CFSW; advanced welding; surface roughness.

\section{Introduction}

Based on the abilities of UAM technique and to overcome the problem owned by a conventional milling method, the paper of, R. Azlan, et al. [1] is made to assess the UAM technique for machining hardened AISI D2 material intending to improve the machined surface. Experiments of ultrasonic-assisted milling are conducted to study the surface roughness during slot cutting operation. From the conducted investigation, the surface roughness values are improved from $0.60 \mathrm{~mm}$ with a non-ultrasonic operation to $0.26 \mathrm{~mm}$ with ultrasonic operation at [37 $\mathrm{m} / \mathrm{min}$-cutting speed, $65 \mathrm{~mm} / \mathrm{min}$-feed rate, and 0.4 $\mathrm{mm}$-depth of cut]. The result shows that the machine surface of slot milling cutting when using ultrasonic tool holder assisted much improved compare to nonultrasonic tool holder machine surface. In addition, it shows that, the surface area of the slot cutting using ultrasonic very smooth as compared to non-ultrasonic slot cutting. Machined surface with ultrasonic tool holder assisted milling to become consistent scaly, structured and exact smooth compare to conventional cutting. Poor machined surfaces and high tool wear rates are the problems associated with the conventional machining of this material. To solve these problems, the paper of, Ramli, et al. [2] proposed a hybrid machining process by adding an ultrasonic transducer to the normal tooling system namely [ultrasonic assisted machining (UAM)]. Experimental work consisted of a comparison between ultrasonic-assisted machining and conventional machining for the different parameters [the cutting speed, the feed rate, and the machining depth] to validate the effectiveness of the proposed method in improving the surface roughness value for machining the hardened AISI D2 material. The factorial design with three factors is employed as the technique of design of experiment (DOE). The results of the machining showed that the presence of rotary ultrasonic-assisted vibration significantly improved the machined surface roughness with up to $(85 \%)$ reduction in $(\mathrm{Ra})$ value compared to the conventional machining process with the same used parameters. Furthermore, the macroscopic observation of the machined surface showed that the surface produced from ultrasonic machining was uniform with consistent peak-to-peak value, which improved the surface finish. In the paper of, Cini Babuji, et al. [3], the optimization of the parameters related to the 
rotary ultrasonic machining of Silicon Carbide is studied. It is well known the Silicon Carbide is a highly brittle material, which is difficult for conventional machining and have a wide range of application in an aerospace industry like space mirrors etc. Various parameters are used in rotary ultrasonic machining of silicon carbide (Sic) is investigated for obtaining a good surface finish and higher material removal rate. Two methods are used (Minitab 17) and (Taguchi technique) for the design of experiments and analyze the results. In addition, assenting test is conducted to validate the results and it is confirmed through Scanning Electron Microscope (SEM) imaging. The research indicates that for maximum surface finish the optimum combination of parameters are identified. An orthogonal array with Taguchi analysis is used to optimize performance characteristics in the machining of Sic. The results presented that, the effect of frequency, spindle speed, feed, and depth of cut on the output parameters. The results obtained are validated using an experimental method and SEM analysis. In the work of, Xiaofen Liu, et al. [4], the theory of the machined surface generation is analyzed and the influences of the cutting parameters and the ultrasonic vibration on the machined surface are investigated by using ultrasonic vibration-assisted milling of TiB2 particle-reinforced aluminum matrix composite. In the first, the motion trajectory of the cutting tool and the machined surface topography generation are analyzed theoretically, and then, the theoretical model of the number of vibration per cutting arc length and the transient angle is built to analyze the cohort of the surface topography. At last, the experiments with and without the ultrasonic vibration are carried out for the theoretical analysis of the machined surface generation and the surface roughness. The results indicated that the regular micro-dimples are produced on the machined surface due to the addition of ultrasonic vibration. From the analysis, the theoretical model could apply to describe the influence of ultrasonic vibration on the surface topography and the roughness. Moreover, this work can assist ultrasonic vibration to improve the surface quality in certain cutting conditions of cutting speed below $(65.94 \mathrm{~m} / \mathrm{min})$ and the vibration frequency of $(20 \mathrm{kHz})$. Najib A. Muhammad, ChuanSong $\mathrm{Wu}$ [5], presented a study to evaluate the influences of ultrasonic vibration on the surface, the electrical and the mechanical behaviors of aluminum to copper dissimilar friction stir welds. Aluminum and copper are joined in different types of base material positions by friction stir welding and ultrasonic vibration-assisted friction stir welding. It is found that the roughness of the weld surfaces is reduced with the addition of ultrasonic energy during the welding, mainly in the type (I) joints. In addition, the aluminum/copper joint strength is increased with a decrease in the intermetallic compounds layer thickness and sizes of the distributed copper particles in the type (I) and type (II) joints, respectively. The change in the strength appeared higher when copper is placed at the retreating side due to the aspect of mixing mechanisms between the aluminum and the copper in the stir zone, which established aspects of distributed copper particles. The major principal strain distribution along the cross-section of the welds as well as fracture step processes (strain evolution, crack inception, and dissemination) of friction stir welding and ultrasonic vibration-assisted friction stir welding joints is investigated using the digital image correlation technique. The welds performed with ultrasonic energy did not experience any form of improvement of the electrical conductivity. The surface roughness is found to be reduced with the presence of ultrasonic vibration, especially in type I joints that have uniform surface formation features. From the results, $\mathrm{Al} / \mathrm{Cu}$ joint strengths are increased with the decreasing the IMCs layer thickness in type (I) joints and the reduction of particle sizes in type (II) joints. When increasing ultrasonic vibration enhanced $\mathrm{Al} / \mathrm{Cu}$ joint strength is become higher in type (II) joints than in type (I) joints. The presence of ultrasonic vibration does not influence the improvement of electrical conductivity of the welded joints in both measured specimens. This paper of, Hong-Xiang, et al. [6] investigates the formation process of surface/subsurface damage in the rotary ultrasonic machining of BK7 glass. The results show that at milling when used end face of the tool, the cutting depth, and the residual height between the abrasive grains constantly change with the high-frequency vibration, generating many cracks on both sides of the scratches. The high-frequency vibration accelerates the chips falling from the surface so that the chips and thermal damage are reduced, causing the surface better quality. A plastic deformation area is formed during the process, due to the non-uniform cutting force on the material surface, and the residual stress is produced in the deformation area, inducing the median/lateral cracks. In the present work of, Omolayo M. Ikumapayi, Esther T. Akinlabi,[7] aluminum alloy 7075-T651 is studied under different reinforcement conditions. The microchannel of dimension $[3.5 \mathrm{~mm}$ depth and $2.0 \mathrm{~mm}$ width] is machined on the aluminum plates to accommodate the particles. The process is made at a different rotational speed of $1200 \mathrm{rpm}, 1500 \mathrm{rpm}$, and $1800 \mathrm{rpm}$ with a constant processing speed of 20 $\mathrm{mm} / \mathrm{min}$, plunge depth of $0.3 \mathrm{~mm}$, and tilt angles of $3^{\circ}$. Double passes are achieved for each parameter with $100 \%$ inter-pass overlap. A cylindrical tapped, 
AISI H13 steel tool with shoulder diameter $18 \mathrm{~mm}$, pin length of $5.0 \mathrm{~mm}$, pin diameter $5 \mathrm{~mm}$ at the top, and $6 \mathrm{~mm}$ at the end with $10^{\circ}$ taper is used during the friction stir process. Surface integrity analysis is carried out with the assistance of the Mitutoyo surf test SJ-210 surface roughness tester (SRT). The analysis is made at three different points on a parameter for a particular workpiece and the average reading for each parameter is calculated to ensure the precision of the measurements and the coverage surface area. The following surface roughness parameters [arithmetical mean roughness value $(\mathrm{Ra})$, maximum height (Ry), mean roughness depth (Rz) and root mean square roughness (Rq) are measured and recorded. Force feedback from the machine data for selected reinforcement particles concerning processing times and $\mathrm{x}$-positions are presented. Friction stir welding (FSW) of 6-mm-thick plates of AA6061-T651 is carried out using a simple cylindrical pin tool in the work of, Rajesh Kumar Bhushan, Deepak Sharma, [8]. The influence of welding parameters such as rotational speed, welding speed on tensile properties, micro hardness, and surface roughness of FSW joints are studied. The universal testing machine (UTM) is used for testing the Ultimate tensile strength (UTS), yield strength, and \% elongation of the AA6061-T651 base plate. The maximum value of (UTS) and the yield strength are achieved at the rotational speed of $1400 \mathrm{rpm}$ and the welding speed of $20 \mathrm{~mm} / \mathrm{min}$. The minimum values of surface roughness are reached at rotational speeds of $1400 \mathrm{rpm}$ and welding speed of $20 \mathrm{~mm} / \mathrm{min}$ and the surface roughness results of the welded region showed that the rotational speed has a significant effect on the surface properties of welds. The microstructural evolutions in the friction stir welded (FSW) joint and micro hardness profile are also determined and Microstructural analysis of the FSW joint shows uniform distribution of particles. The maximum hardness of HV 120 is achieved for SZ, while the boundary between HAZ and TMAZ on the advancing side exhibited the lowest hardness value of HV 81. Finally, attainment of the maximum tensile strength, micro hardness, and minimum surface roughness during FSW is the desired method to improve the service life and suitability of AA6061T651. Many researchers have been working on the new methods, as problems due to fusion welding are not being solved in the case of brass. Friction stir welding is one of the novel methods to solve many problems. So, experimental investigations in the work of, P. V. Chandra Sekhara Rao, et al. [9] are necessary for this field. These research works are reported on FSW of Aluminum, copper, and their alloys, but constrained work has been done in the case of brass. In this work, the optimum parameters for FSW of brass and corrosion test, tensile test, environmental tests, surface morphology, and surface metallurgy results have been examined on the obtained weld joints. The poor machined surface and the high tool wear rate are among the problems associated with the conventional machining of the mold and die applications. To decrease these problems, this paper of, Azlan Ramli, et al.[10] proposed a hybrid machining process by adding an ultrasonic transducer to the normal tooling system namely ultrasonic assisted machining (UAM). The used parameters are, the cutting speed, the feed rate, and the machining depth, the factorial design is employed as the technique of design of experiment (DOE). A comparison between ultrasonic-assisted machining and conventional machining to validate the effectiveness of the proposed technique in improving the surface roughness value for machining hardened AISI D2 material. The results showed that the presence of rotary ultrasonic-assisted vibration significantly improved the machined surface roughness with up to $85 \%$ reduction in $(\mathrm{Ra})$ value compared to the conventional machining process with the same cutting conditions. Furthermore, the macroscopic observation of machined surfaces showed that the surface produced from ultrasonic machining is uniform with consistent peak to peak value which improved the surface finish. From this work, the best selection of machining parameters with rotary ultrasonic-assisted machining is [0.6 $\mathrm{mm} / \mathrm{min}$ - cutting speed, $5 \mathrm{~mm} / \mathrm{min}$-feed rate, and 12 $\mu \mathrm{m}$-depth of cut with $0.27 \mu \mathrm{m}$ ] of surface roughness value. The statistical analysis (ANOVA) shows that the cutting speed, the feed rate, and the ultrasonicassisted machining are the major parameters that influence the surface roughness value. The cutting process by micro surface topography shows that the machined surface by ultrasonic-assisted machining is very smooth with the consistency of feed mark that contributes to the excellence of surface quality. In addition, this work proves that the rotary ultrasonicassisted machining successfully improves the machining accuracy with the reduction of $(\mathrm{Ra})$ values and consistency of feed mark with the low tool vibration. In the paper of, Saqib Anwar, et al.[11] an adaptive neuro-fuzzy system is applied to predict the surface roughness and exit chipping during drilling of BK7 glass by using rotary ultrasonic machining (RUM). This has been accomplished by study the influence of the different machining variables such as the spindle speed, the feed rate, and the ultrasonic vibration on surface roughness and exit chipping size that are directly linked with the quality of the drilled hole. The results of the ANFIS models are compared with both the experimental data and the commonly used response surface method (RSM). The results 
revealed that the ANFIS model could accurately predict surface roughness and exit chipping size for both training data and testing data. Furthermore, from the comparison ANFIS model could predict the surface roughness and exit chipping size for training data with MAPE $0.44 \%$ and $6.29 \%$ respectively. For the same training data, the regression models generate higher MAPE of $3.76 \%$ and $9.99 \%$, respectively. But for testing data, the ANFIS models show MAPE of $5.05 \%$ and $4.88 \%$ for surface roughness and exit chipping size respectively, while regression models exhibit higher MAPE of 5.15\% and $12.65 \%$, respectively. Hence, the developed model using the ANFIS approach can be used effectively to predict surface roughness and exit chipping size and provides more reliable results as compared to the RSM approach. The aim of the research of, Adirek Baisukhan, Wasawat Nakkiew [12] is to investigate the sequence of processes for improving the welded surface integrity of AA7075T651 aluminum alloy joined by friction stir welding (FSW). The used development processes include mechanical surface improvement with deep rolling (DR) and post-weld heat treatment (PWHT). In this research, the following parameters are studied; the welded surface integrity, which comprises residual stress, the micro hardness, the surface roughness, the microstructure, and the fatigue life. Three combinations sets of experiments; In the first, only FSW is applied, in the second, FSW is applied followed by DR, and then PWHT processes (FSWDR-PWHT); and in the last set, FSW is applied, followed by PWHT, and then DR processes (FSWPWHT-DR). The results indicated that the residual stress plays a significant role in the fatigue life and the fatigue test showed that FSW workpieces subject to the PWHT process followed by the DR process (FSW-PWHT-DR) had the highest fatigue life, with an increase of $239 \%$ when compared with unprocessed FSW workpieces. In addition, nearsurface compressive residual stress has confirmed that a great influence on fatigue life of the welded joint due to the near-surface compressive residual stress can prevent or reduce fatigue surface crack initiation as well as surface fatigue crack growth. Comparatively, it is found that the FSW-DR-PWHT workpiece resulted in the fatigue life of the material being reduced by up to $26 \%$ when compared with the FSW as-welded workpiece and the results of the DR process, the last step of treatment, is that the DR process can enhance the fatigue life. The DR process develops the surface roughness to a level equivalent to that of the grinding process with the $(\mathrm{Ra})$ values in the longitudinal and transverse directions of the FSW-PWHT-DR workpiece at $[0.15 \mu \mathrm{m}$ and 0.07 $\mu \mathrm{m}]$, respectively. The PWHT process relaxes near- surface residual stress during aging treatments but will increase the hardness value as well as improve the hardness uniformity. From the measured values, which were established by the last step of the treatment, it is found that the greatest benefit concerning both treatment process sequences, was yielded when the workpiece was the first subject to the PWHT process followed by the DR process (FSW-PWHT-DR). The application of 6005A aluminum alloy in transportation is increasing, which puts forward higher requirements for the fatigue performance of the welding process. In this study of, Hongxuan Wang, et al. [13], friction stir welding (FSW) enhanced treatment is applied on the traditional metal inert gas (MIG) weld. From the analysis of the results, the fatigue life of the FSW plate is three times higher than that of the original MIG welded plate at $140 \mathrm{MPa}$ stress level. Lower than 107 cycles, the fatigue life limit is increased by $16 \mathrm{MPa}$ compared with the as-received MIG plate. The major reason for FSW leading to the increasing fatigue life is the reduction of porosity to reduce the crack initiation and the grain refinement to delay crack propagation. Ahmadnia, et al. [14] investigated the influence of the welding parameters (i.e. the ultrasonic power, the rotational speed, the traverse speed, and the axial force) in the UAFSW process on the mechanical and tribological properties of AA 6061 joints. The experiments are conducted according to the L9 Taguchi design. The goal is to maximize the formability and tensile strength as well as, minimizing the surface roughness and sliding wear rate once as a single-objective optimization problem using Taguchi technique and again as a multi-objective optimization problem using grey relational analysis. The material at the bottom region of the joint is subjected to less temperature compared to the upper region. Then it is a more need for acoustic energy to improve its flow characteristics. When applied the ultrasonic vibration on the bottom surface of the workpiece in a process known as (UVBS-FSW), improves the flow characteristics. In the research of, Liu, et al. [15], they have examined and analyzed the precipitates at different zones of the joint, and the prismatic dislocation loops and highdensity helical dislocations were examined. The results showed that there is a significant increase in vacancy density. Thereby, the climb of edge and jogs dislocations are both improved, and hence, the material deformation resistance can be reduced. In other words, the acoustic-plastic effect causes a highdensity vacancy, leading to an enhancement in the mobility of dislocations. In the present work of, Masoud Ahmadnia, et al. [16], a vertical highfrequency vibration is applied on friction stir tool to determine its influences on the formability 
characteristics of mechanical properties, as well as surface quality and the tribological properties of the welded specimens of AA6061. Taguchi design (L9) is used to conduct the experiments and analyze the influence of the factors on the mentioned quality characteristics. The major used parameters are the ultrasonic power, the tool rotary speed, the traverse speed, and the axial force. In addition, the optimal welding conditions are identified using grey relational analysis to maximize the tensile strength and formability and minimize the surface roughness and sliding wear rate. From the analysis of the obtained results, the increase in ultrasonic vibration power significantly developed both mechanical and tribological properties of AA6061welded specimens and it means that it increases both tensile strength and Erichsen number and decreases both surface roughness and wear rate. Also, the joints fabricated at [400WUS power, $1000 \mathrm{rpm}$ tool rotary speed, 40 $\mathrm{mm} / \mathrm{min}$ traverse speed, and $8 \mathrm{kN}$ axial force] have higher tensile strength than the other joints. When the joints are fabricated at [400WUS power, $1200 \mathrm{rpm}$ tool rotary speed, $40 \mathrm{~mm} / \mathrm{min}$ traverse speed, and 12 $\mathrm{kN}$ axial force], these joints have a higher Erichsen number than other joints. The joints fabricated at 400WUS power, 1,200 RPM tool rotary speed, 40 $\mathrm{mm} / \mathrm{min}$ traverse speed, and $4 \mathrm{kN}$ axial force have lower surface roughness than other joints. But, the fabricated joints at [400WUS power, $1000 \mathrm{rpm}$ tool rotary speed, $40 \mathrm{~mm} / \mathrm{min}$ traverse speed, and $8 \mathrm{kN}$ axial force] these joints have a lower sliding wear rate than other joints. The optimization through grey relational analysis revealed that selecting [US vibration power of $400 \mathrm{~W}$, tool rotary speed of 1000 RPM, traverse speed of $40 \mathrm{~mm} / \mathrm{min}$, and axial force of $12 \mathrm{kN}$ ] causes the highest value of tensile strength and Erichsen number, as well as minimum surface roughness and wear rate. The main objective of the research of, Ankit Sharma, et al. [17] is to optimize the best parametric combination to attain the least amount of surface roughness. The three used parameters, for design the experiment [L 18 optimization technique is used], are the spindle speed, the ultrasonic amplitude, and the feed rate. The least value of surface roughness is noticed at spindle speed (5000 rpm), vibration amplitude $(20 \mu$ $\mathrm{m})$, and feed rate $(6 \mathrm{~mm} / \mathrm{min})$ which be adopted for increasing its functional application. Consequently, after optimizing the parameters, the least value of surface roughness at the hole internal region is revealed as $1.09 \mu \mathrm{m}$. The optimized parameters to get the least values of the surface roughness are the spindle speed $(5000 \mathrm{rpm})$, the feed rate $(6 \mathrm{~mm} / \mathrm{min})$, and the vibration amplitude $(20 \mu \mathrm{m})$. The influence of the welding process parameters such as the tool rotational speed and the feed on the temperature, the axial force, and the quality of the joint surface is studied in the work of, M A Constantin, et al. [18]. The study shows that the temperature in the FSW process depends on the two parameters, increasing with the increase of the tool rotational speed and with the reduction of the welding feed and the tool rotational speed having a major effect in this case. The axial force does not show an explicit dependence on the two technological parameters, due to the two complex mechanisms that influence it and which are done at the same time, (the material plasticization and friction between the tool and the material). The FSW joints present two types of surface defects, channels, and excessive burrs. The channel defect is determined by the insufficient penetration of the tool in the joining structure and by the low process temperature, while the excessive burr type defect is caused by very high process temperatures. Moreover, the increasing the temperature to higher than $650{ }^{\circ} \mathrm{c}$ leads to excessive plasticization of the material and, hence, to the appearance of excessive burrs and to the increase of roughness and when the tool rotational speed is increased the FSW joints roughness is increased and the tool rotational speed having a greater influence in this dependence as well. In the research of, Jatinder Kumar, J. S. KhambaII [19], the optimization of the process parameters in the ultrasonic machining of pure titanium (ASTM GradeI) using the Taguchi method is studied. Four different process parameters are used, [tool material, abrasive material, grit size of the slurry used, and power rating of the machine]. The responses that are investigated are tool wear rate and the quality of the machined surface in terms of the surface finish and the material removal mechanism is also studied with the machining conditions. The tool wear rate is found to be increasing linearly with the increase in the grit size of the abrasive slurry used. The use of a higher power rating leads to more TWR. The quality of the machined surface depends primarily on the grit size of the abrasive used and the power rating of the ultrasonic machine. The optimum process conditions for both the response variables (TWR, surface roughness) are identified. Hence, it can be established that in ultrasonic drilling of pure titanium, tool wear rate and surface quality obtained are highly interrelated; optimization of one contributes strongly to optimization of the other as well. In the paper of, M. Merklein and H. Hagenah [20], the influence of applying vibration on FSW is investigated in simulating tools. In this case and for FSW modeling, a proper transfer function of axial force is proposed and the resultant axial force of conventional FSW and Vibration Assisted FSW (VAFSW) are compared in frequency and time domain state spaces. A decent correlation between FSW simulation and experiments 
is observed. For more investigation of VAFSW, the response surface of design of experiment (DOE) method is utilized and the influence of changing VAFSW process parameters is investigated. The simulation results indicated that the vibration helps to decrease the welding force and when using the (DOE) method the effects of implemented frequency and vibration speed amplitude in FSW are found. The paper of, Gianluca D'Urso, et al. [21] deals with the setup of a FE model for the simulation of the FSW process. The results are correlated with the experimental observations carried out when joining AA6060-T6 aluminum alloy plates $(5 \mathrm{~mm})$ thick with a cylindrical tool with a flat shoulder. The experiment is performed under different welding conditions varying as the tool rotational speed and the welding speed. A three-dimensional piezoelectric load cell is used to measure the welding forces in the fundamental directions. The numerical model is established and set up in DEFORM 3D environment. The information is obtained from the model helped in the understanding of the welding phenomena. Ultrasonic-assisted friction stir butt-welding on aluminum alloy V95AT1 (7075) has been studied in the work of, S. Yu. Tarasov, et al. [22]. The used samples are characterized using metallography, micro-hardness, and XRD. The ultrasonic treatment during welding provides extra plasticizing of metal and better stirring efficiency. This is used for elimination the defects, such as root flaws and grain refining in the stir zone. From the results, the stress state in the welded joint is characterized by tensile strength in the direction of the weld seam centerline and compression in the transversal direction. The ultrasonic treatment can be used to increase the compression stress and relieve the tensile one. In the study of, Mohamadreza Nourani, et al.[23] is planned to optimize the process parameters of friction stir welding (FSW) of 6061 aluminum alloy. In particular, it is studied how to minimize the heataffected zone (HAZ) distance to the weld line in the joined parts using a Taguchi optimization method and a temperature-field finite element model. The highest temperature during the process has also been minimized. As the method is used for the first time with the HAZ objective function, an auxiliary full factorial search is conducted to ensure Taguchi's orthogonal design assumption for the FSW problems. Results approve that the method can use for minimizing both the HAZ distance to the weld line and the peak temperature, with a minimal number of simulation runs via orthogonal arrays. Furthermore, a new ANOVA analysis on the L9 orthogonal array with three factors is performed and the results indicate that among the parameters considered (i.e., the tool rotational speed, transverse speed, and the axial force), the most significant parameter on the weld quality is the rotational speed, followed by the axial force and transverse speed. Mishra R, Jain S, [24] applied the Taguchi technique on the FSW process of AA 6082-T6 to obtain the optimum combination of process parameters to achieve the best ultimate tensile strength. The rotational speed, the welding speed, the pin profile, and the tool shoulder diameter are the input process variables that have been used at four levels with a total number of 16 experiments. ANOVA analysis is also performed to determine the influence percentage of each parameter. It is shown that the optimum combination is a rotational speed of $1200 \mathrm{rpm}$, a welding speed of $30 \mathrm{~mm} / \mathrm{min}$, a tool with a cylindrical threaded pin, and a shoulder diameter of $16 \mathrm{~mm}$. Rostamiyan, et.al. [25] analyzed the influence of the process parameters such as the ultrasonic vibration, the rotational speed, the tool plunge depth, and the dwell time on the hardness and the lap shear force (LSF) by developing the L18 Taguchi design. The influence percentage of each parameter is also calculated using analysis of variances. It is showed that the ultrasonic vibration has a favorable effect on both LSF and hardness of the welded joints and has the highest contribution percentage. The optimum condition is determined by grey relational analysis and a combination of applying ultrasonic vibration, $1200 \mathrm{rpm}$ rotational speed, $6 \mathrm{~mm}$ tool plunge depth and $6 \mathrm{~s}$ dwell time is found to achieve the maximum LSF and hardness. The process parameters in FSW of AA 5083 are modeled and analyzed by Kundu, et al. [26] using response surface methodology (RSM). The experiments are conducted according to a central composite design with a total number of 30 experiments. The process parameters are the traverse speed, the rotational speed, the tool tilt angle, and the dwell time. The responses in the model are the tensile strength and the elongation. Practical relationships are established between the input process parameters and the responses. The established models have shown that tool rotational speed and the tool tilt angle have more main influence on the responses as compared to other parameters.

From the previous literature review, the process of friction stir welding (FSW) offers numerous advantages over the other welding methods and it can used also to join dissimilar materials. This method of welding needs more investigations and analysis because it has some certain limitations such as high welding loads, high torque needed, and low welding speeds. Therefore, in this work, the independently controllable parameters, which have a large influence on the surface quality of welded joints, are studied and analyzed. 


\section{Experimental work}

\subsection{Materials and used Tools}

In the present research, the material of the welded butt joint is Aluminum alloy 6082-T61. The Aluminum sheet is prepared to the required dimension samples of $(160 \times 100 \times 3) \mathrm{mm}$. The chemical composition and mechanical properties of AA6082-T61 as received from the supplier are shown in Tables (1 and 2) respectively.

The diameter of the used pin is estimated as a ratio of the shoulder diameter, approximately $1 / 3$ of the shoulder diameter [27]. So that, a pin diameter of 4.6 $\mathrm{mm}$ is used as a rule of thumb, the pin length is approximately $0.85-0.95$ of the workpiece thickness [28]. Thus, a pin length of $2.85 \mathrm{~mm}$ is used. The used vibrating tool head is made of titanium with $(22 \mathrm{~mm}$ tip diameter and $100 \mathrm{~mm}$ length) and is used to generate ultrasonic vibration waves at a frequency of $24 \mathrm{kHz}$, a power of 85 watt and adjustable amplitude up to 100 , and the ultrasonic processor (model up $400 \mathrm{~S}$ ) is used in these experiments to obtain the required ultrasonic vibration. The used FSW tool is shown in Fig. (1-a), with various quantities [29] and the operation of welding is shown in Figs, $(1, \mathrm{~b}-\mathrm{c})$. From this figure, it can calculate all the resultant forces during welding as follow;

Table (1) Chemical composition of AA6082-T61,wt. \%

\begin{tabular}{|ccccccccc|}
\hline $\mathrm{Si}$ & $\mathrm{Fe}$ & $\mathrm{Cu}$ & $\mathrm{Mn}$ & $\mathrm{Mg}$ & $\mathrm{Cr}$ & $\mathrm{Ni}$ & $\mathrm{Ti}$ & $\mathrm{Al}$ \\
\hline $\begin{array}{c}-0.7 \\
1.3\end{array}$ & 0.5 & 0.1 & 0.7 & 0.9 & 0.25 & 0.2 & 0.1 & $\mathrm{REM}$ \\
\hline
\end{tabular}

Table (2) Mechanical properties of AA6082-T61

\begin{tabular}{|cccc|}
\hline UTS & YS & $\begin{array}{c}\text { Eleonga } \\
\text { tion } \\
\text { MPa }\end{array}$ & $\begin{array}{c}\text { MPa } \\
\text { HB } \\
\text { HB }\end{array}$ \\
\hline 250 & 185 & 21 & 80 \\
\hline
\end{tabular}

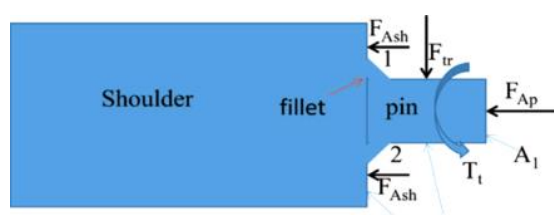

$\mathrm{A}_{3} \quad \mathrm{~A}_{2}$

Fig. (1-a) The forces analysis at the FSW tool.

From Fig. (1-a);

$\mathrm{FAp}+\mathrm{FAsh}=\mathrm{FA}=12.326 \times 103 \mathrm{~N}($ from FSW

machine computer)

$\mathrm{FAp} / \mathrm{FAsh}=\mathrm{Ap} / \mathrm{Ash}$

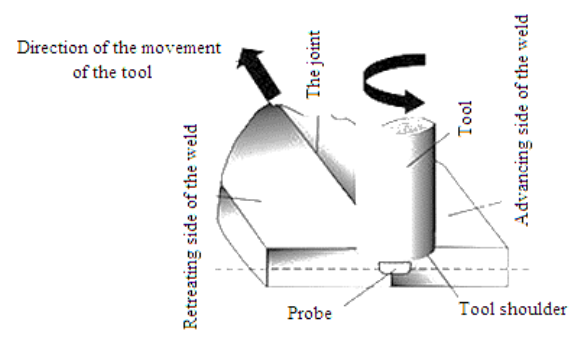

(1-b) Beginning of operation.

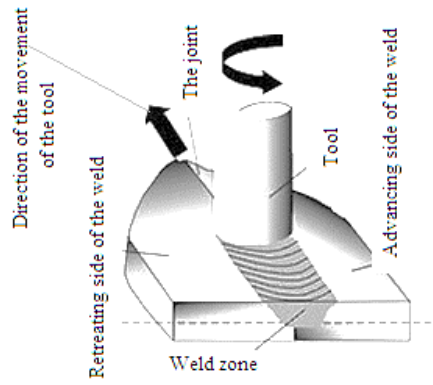

(1-c) The operation of welding.

Fig. (1) The FSW tool and the operation of welding, [29].

\subsection{Analysis of operation during welding}

At the processes of conventional welding, the heat is provided from the external certain power source but in the friction stir welding (FSW), the welding process itself generates the heat. The heat generation in friction stir welding is causing by two mechanisms, the friction, and the plastic deformation during the welding process.

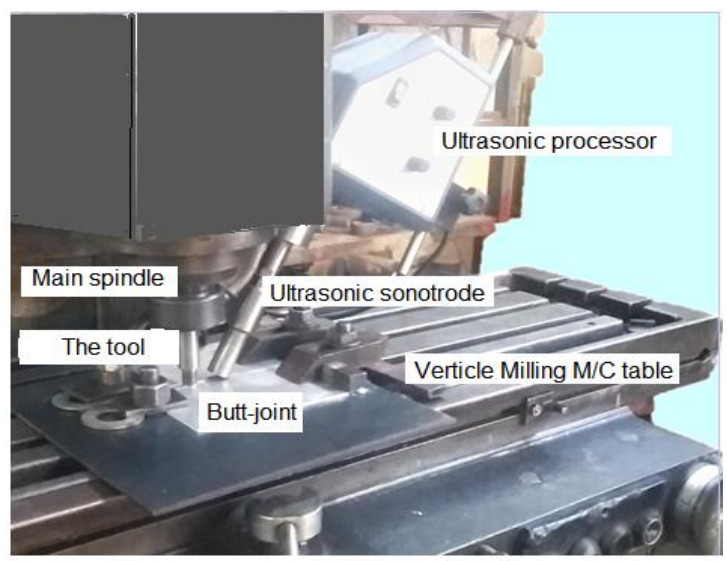

Fig. (2) The welded operation setup,[30] 
The importance of the heat generation, the heat transfer, and the material flow deliver a defect-free quality friction stir welded joint. The ultrasonic processor is fixed on the head of a milling machine via a fit attachment and the tool (sonotrode) moves along the welding line ahead of the friction stir welding tool by a distance of $25 \mathrm{~mm}$ and with an inclination angle between the axis of the (sonotrode) and the workpiece surface of $60^{\circ}$ to keep it away from the tool. Thus, the waves of the ultrasonic vibration transmitted directly into the localized area of the workpiece without any losses in the transmitted energy compared to other methods for transmitting the ultrasonic vibrations, and the welded operation setup is shown in Fig. (2), [30].

\subsection{The used parameters of the experiment}

The used welding parameters, which are having greater influences on welding joint quality at the UVFSW process, are; the rotational speed, the traverse speed, the amplitude. These parameters are listed in Table (3). The experiments are designed to achieve a comparative study between friction stir welding and ultrasonic-assisted friction stir welding and the comparison is made at a constant rotational speed of $1500 \mathrm{rpm}$ and at different welding speeds of $(80,120,140$, and $160 \mathrm{~mm} / \mathrm{min})$, to examine the effect of ultrasonic vibration on the surface roughness and the resulting welding defects.

Table (3) process parameters and their levels.

\begin{tabular}{|l|l|l|l|l|l|}
\hline $\begin{array}{l}\text { Process } \\
\text { parameter }\end{array}$ & Range & $\begin{array}{c}\text { Level } \\
1\end{array}$ & $\begin{array}{c}\text { Level } \\
2\end{array}$ & $\begin{array}{c}\text { Level } \\
3\end{array}$ & $\begin{array}{c}\text { Level } \\
4\end{array}$ \\
\hline $\begin{array}{l}\text { Rotational } \\
\text {-speed } \\
\text { rpm }\end{array}$ & $600: 1200$ & 600 & 800 & 1000 & 1200 \\
\hline $\begin{array}{l}\text { Welding } \\
\text {-speed } \\
\text { mm/min }\end{array}$ & $80: 160$ & 80 & 120 & 140 & 160 \\
\hline $\begin{array}{l}\text {-Amplitude } \\
\mu m\end{array}$ & $40: 100$ & 40 & 60 & 80 & 100 \\
\hline
\end{tabular}

\subsection{Surface roughness measurement of the welded area}

The welded area is prepared for measurements and the measurements are made five times [at the beginning of welding, and the middle and at the end]. These measurements are made after the calibration of the instrument (SJ-201P surface test), and with the cut-off length of $(0.8 \mathrm{~mm})$ according to (ISO 4287 1997). The average values of the five measurements of the surface roughness of the welded areas are considered for the investigation.

\section{Results and discussion}

3.1. Effect of the ultrasonic vibration on the mechanical properties

The effect of ultrasonic vibration on the mechanical properties of welded joints is investigated by using both the tensile and micro-hardness tests. The ultimate tensile strength and the elongation percentage for both conventionally(CFSW) and ultrasonically assisted friction stir welded(UAFSW) samples are compared over a range of welding speeds as shown in figures (3) and (4) to make known the effect of ultrasonic vibration on the tensile properties. The ultimate tensile strength at low and medium welding speeds ( 80 and $120 \mathrm{~mm} / \mathrm{min}$ ) is generally high in both two types of welding, and the ultimate tensile strength is increased by about $16 \%$ in UAFSW than the conventionally (CFSW).

This increase in the ultimate tensile strength may be due to the grain refinement action that has been detected in the microstructural analysis of the stirring zone. A clear decrease in the ultimate tensile strength is shown at high welding speeds (140 and 160 $\mathrm{mm} / \mathrm{min}$ ) especially for conventionally friction stir welded samples. This decrease in the ultimate tensile strength values is due to the obvious defects that have been detected in these samples due to insufficient heat input and improper material flow. At the ultrasonic-assisted samples, the situation is more balanced at high welding speeds, and this is due to the improvement in material softening and flow. For the elongation results, there is a significant reduction in the elongation values whether in conventional FSW or Ultrasonic assisted friction stir welding as compared to the base metal. This is maybe due to the lower homogeneity in conventional FSW and ultrasonic-assisted friction stir welding at different microstructural zones. The elongation is increased when ultrasonic vibration is applied and the percentage of increases are 15 and $7 \%$ is obtained at welding speeds of 80 and $120 \mathrm{~mm} / \mathrm{min}$ respectively.

On the other side, a comparison between the microhardness profiles in the two types of welding at different welding speeds is shown in Figs. (5 and 6) For example and it is clear, the micro-hardness profile resulting from the FSW process is characterized by $\mathrm{W}$-shape. The values of the microhardness slightly decrease in the Thermo mechanicalaffected zone interface from the values at the stirring zone and then raise again until reaching their maximum value at the base metal. As shown in these figures, the micro-hardness profiles for conventional FSW and ultrasonic-assisted friction stir welding are close in most regions except the stirring zone. The values of micro-hardness are higher in ultrasonicassisted friction stir welding than conventional FSW. This development in micro-hardness values in the 
stirring zone is predicted because of the increase in the grain improvement in the stirring zone.

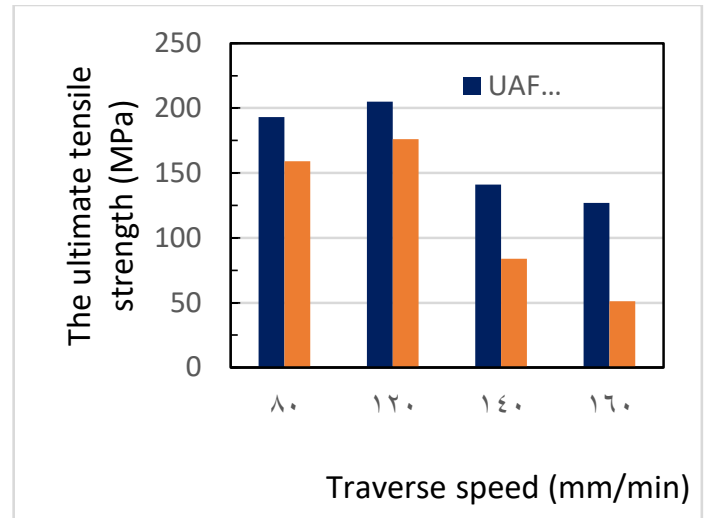

Fig.(3), the relation between the welding speed and the ultimate tensile strength for the two types of welding.

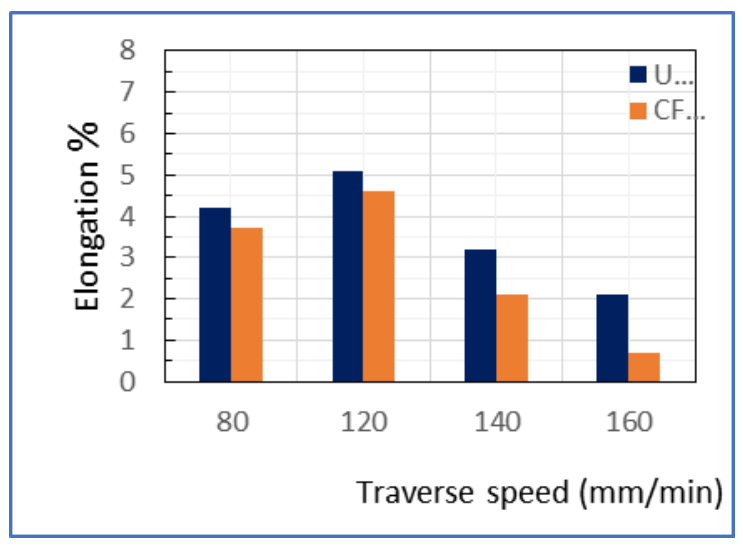

Fig. (4), the relation between the welding speeds and the elongation for the two types of welding.

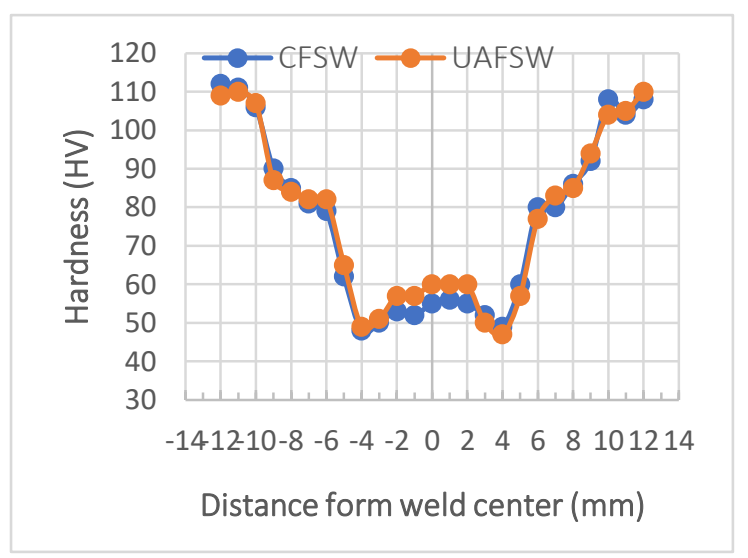

Fig.(5). The hardness of the first same type of specimens for the two types of welding at different distances from the weld center.

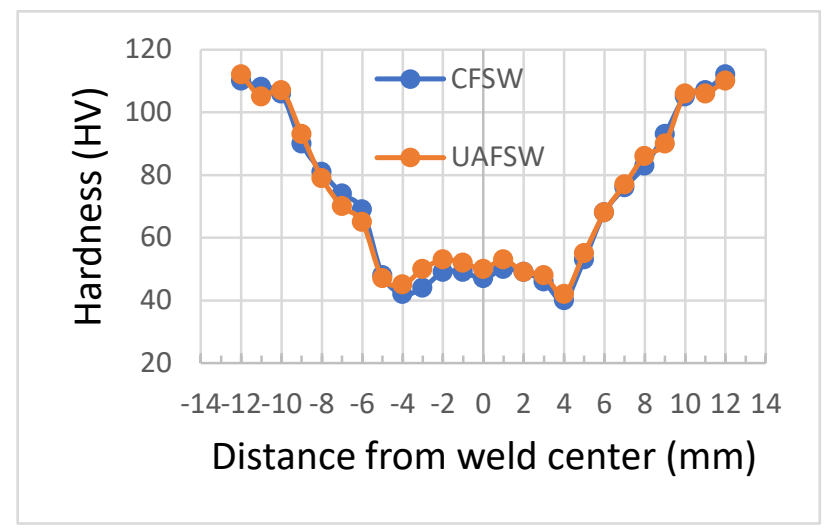

Fig.(6). The hardness of the last same type of specimens for the two types of welding at different distances from the weld center.

\subsection{Inspection of the welded area}

To check the quality of welded joints, the sound inspection method is used because no external defects are shown as evidence of the proper process parameters, heat input, and material flow. But the external defects such as large grooves, voids, and flash are related to improper heat input and material flow. The weld line of conventional FSW and ultrasonic-assisted friction stir welding are shown in Fig. (7). From this figure, it is obvious that the second type of welding FSW gives a better surface as compared with the first one.

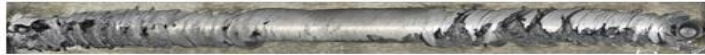

Welding line without ultrasonic when using the same parameters.

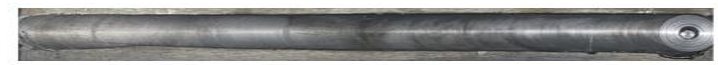

Welding line with ultrasonic when using the same parameters.

Figs. (7) The weld appearance of conventional FSW and ultrasonic-assisted friction stir welding.[30]

\subsection{Surface roughness assessment}

Generally, in the manufacturing process, producing a good finished surface is an important required goal. There are various parameters to test the surface characteristics of the welded specimens such as crack density, surface topography, surface strain, etc. However, in the present research, only the surface roughness $(\mathrm{Ra})$ is measured on the weld area span to analyze the surface 
quality of welded joints. The surface roughness $(\mathrm{Ra})$ is measured for the welded joints at, [ $600 \mathrm{rpm}$ with $80 \mathrm{~mm} / \mathrm{min}, 800 \mathrm{rpm}$ with $80 \mathrm{~mm} / \mathrm{min}, 1000 \mathrm{rpm}$ with 80 $\mathrm{mm} / \mathrm{min}$, and 1200 Rotational speed -rpm with 80 Welding speed- $\mathrm{mm} / \mathrm{min}$ respectively]. The amplitude of 40 is used with all of these parameters. Five measurements are made at the welding span [at the beginning of welding, and the middle and the end]. The average values of the five measurements of the surface roughness of the welded areas are considered for the investigation. In Fig.(8), the average surface roughness measurements at the welded area distance on the span when used the rotational speed, $600 \mathrm{rpm}$, the welding speed $80 \mathrm{~mm} / \mathrm{min}$, and the amplitude of $40 \mu \mathrm{m}$ are plotted. From these results, it is clear that the values of ( $\mathrm{Ra}$ ) are high at the beginning of welding operation ( $\mathrm{Ra}$ nearly about $6.8 \mu \mathrm{m}$ ) and begins to decrease gradually with the progress of welding operation to nearly the distance $10 \mathrm{~mm}$ of span ( $\mathrm{Ra}$ nearly about $4.4 \mu \mathrm{m}$ ) and begin increase slowly at distance $11 \mathrm{~mm}$ from the beginning to the end of welding distance ( $\mathrm{Ra}$ nearly about $5.4 \mu \mathrm{m}$ ). But when used the rotational speed, 800 $\mathrm{rpm}$, the welding speed $80 \mathrm{~mm} / \mathrm{min}$, and the amplitude of $40 \mu \mathrm{m}$, the results of surface roughness ( $\mathrm{Ra}$ ) are changed as shown in Fig.(9). The values of (Ra) are decreased as compared with the previous results shown in Fig. (8). At the beginning of welding, the average value of $(\mathrm{Ra})$ is about $4.8 \mu \mathrm{m}$, and it decreases gradually to $4.3 \mu \mathrm{m}$ at 5,8 and $11 \mathrm{~mm}$ of span length and begins to increase to 3.4 $\mu \mathrm{m}$ at the end of span length.

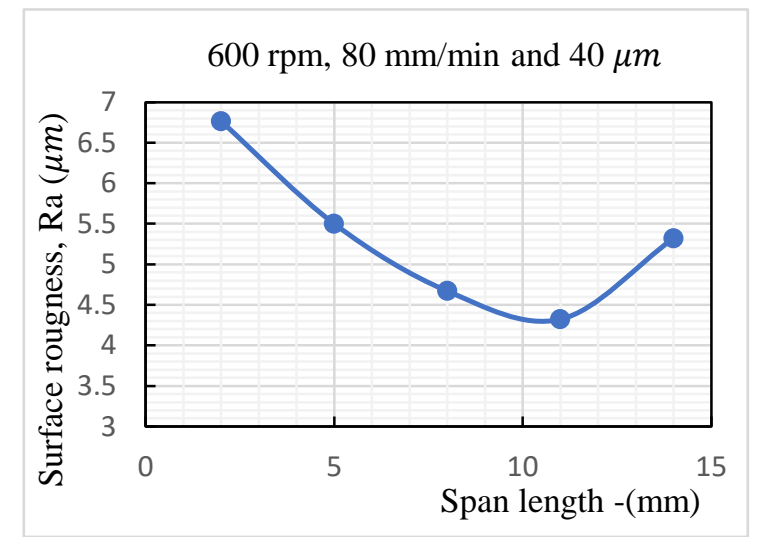

Figs. (8) The surface roughness measurement at the length span of weld line when used $600 \mathrm{rpm}$ and 80 $\mathrm{mm} / \mathrm{min}$.

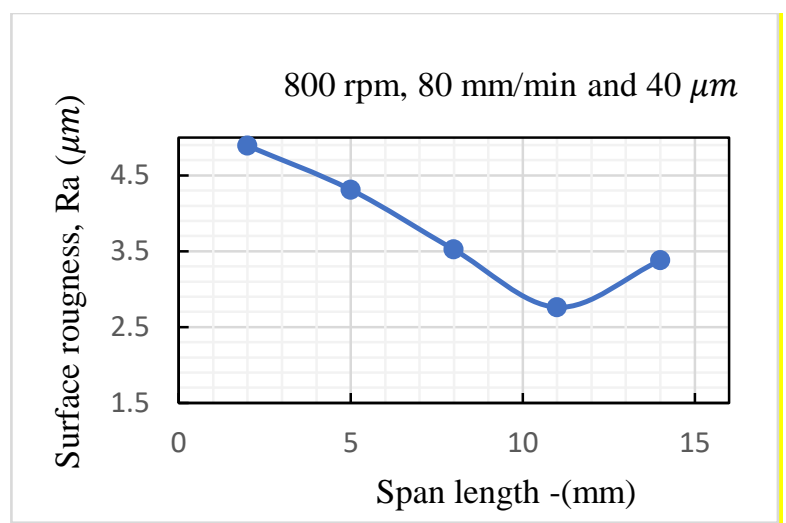

Figs.(9) The surface roughness measurement at the length span of weld line for sample (B)

In Fig.(10), the used parameters are changed to; the rotational speed, $1000 \mathrm{rpm}$, the welding speed 80 $\mathrm{mm} / \mathrm{min}$, and the amplitude of $40 \mu \mathrm{m}$. From this figure, the values of $(\mathrm{Ra})$ are decreased again as compared with the previous two cases. At the first distance of span, it is about $4.4 \mu \mathrm{m}$, and as the previous cases, it begins to decrease to $4.2,3.4$, and $3.1 \mu \mathrm{m}$ at 5,8 and $11 \mathrm{~mm}$ of span length and begin to increase to $3,3 \mu \mathrm{m}$ at the end of span length. In Fig. (11), the average surface roughness measurements at the welded area distance on the span when used the rotational speed, $1200 \mathrm{rpm}$, the welding speed $80 \mathrm{~mm} / \mathrm{min}$, and the same amplitude of $40 \mu \mathrm{m}$ are plotted. Also in these results, the values of average surface roughness are decreased as compared with the three previous cases. At the beginning of welding, the average value of $(\mathrm{Ra})$ is about $4.1 \mu \mathrm{m}$, and it decreases gradually to $3.5 \mu \mathrm{m}$ at 5,8 and $11 \mathrm{~mm}$ of span length and begins to increase to $3.3 \mu \mathrm{m}$ at the end of span length.

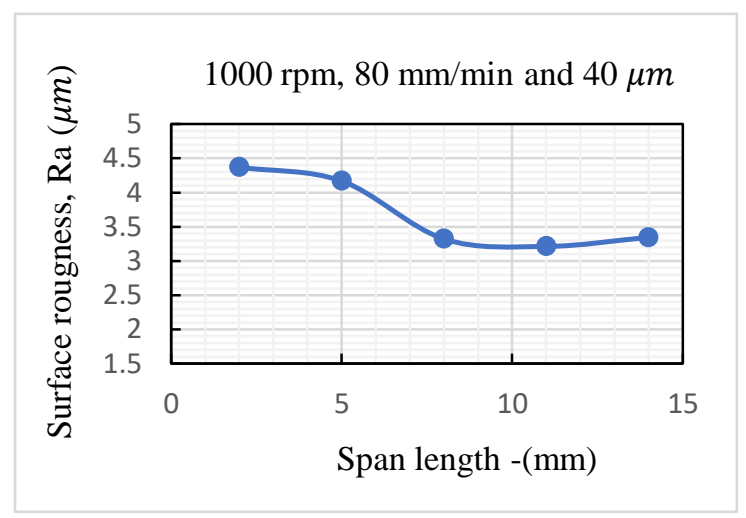

Figs.(10) The surface roughness measurement at the length span of weld line for sample (C). 


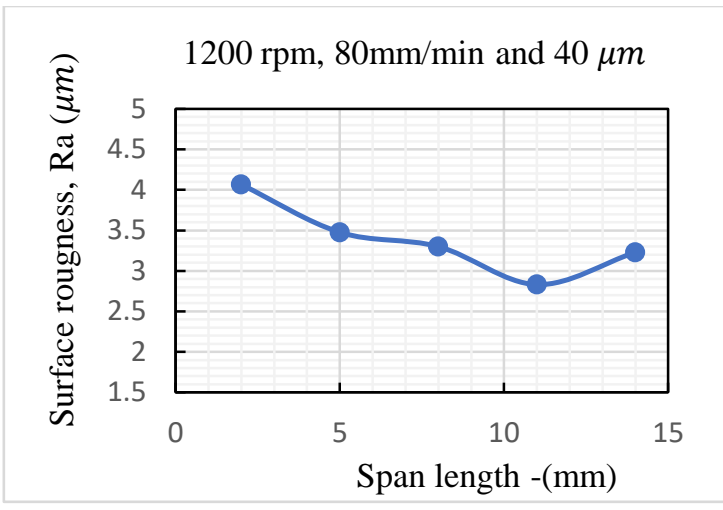

Figs.(11) The surface roughness measurement at the length span of weld line for sample (D)

In Fig.(12), the used parameters are changed to, the rotational speed, $1200 \mathrm{rpm}$, the welding speed 160 $\mathrm{mm} / \mathrm{min}$, and the same amplitude of $40 \mu \mathrm{m}$. The results indicated that the increase of the welding speed to 160 $\mathrm{mm} / \mathrm{min}$, leads to an obvious increase in the surface roughness (Ra). But the results have the same trend as shown in the previous figures. At the beginning of welding, the average value of $(\mathrm{Ra})$ is about $7.65 \mu \mathrm{m}$, and it decreases gradually to $6.33 \mu \mathrm{m}$ at 5,8 and $11 \mathrm{~mm}$ of span length and begins to increase to $5.3 \mu \mathrm{m}$ at the end of span length.

From the previous figures, it is clear that the values of (Ra) are high at the beginning of the welding span for all use of the rotational speeds and the welding speeds.

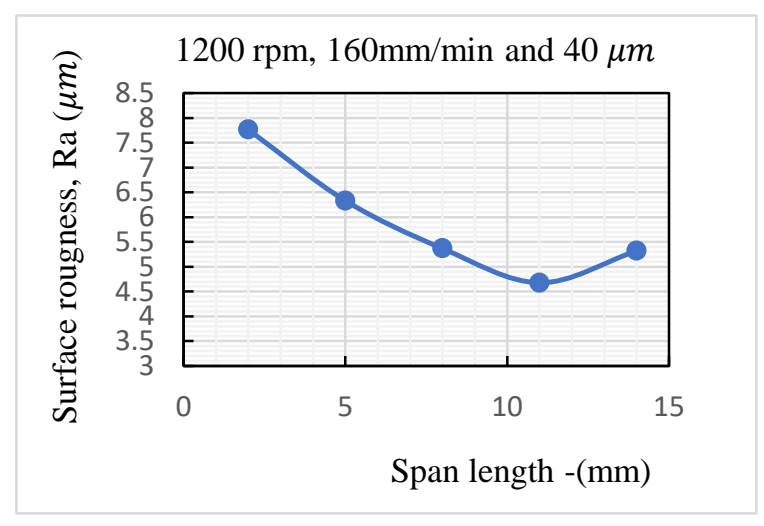

Figs.(12) The surface roughness measurement at the length span of weld line for sample (E)

But in the middle distance of span, the improvement of the surface quality is clear, and at the end of the welding operation, the values of $(\mathrm{Ra})$ is increased but with small values of roughness as compared with the values at the beginning of welding operation. But the higher values of $(\mathrm{Ra})$ are obtained when changed the welding speed from 80 to $160 \mathrm{~mm} / \mathrm{min}$.

From the comparison between the results in the figures
$(8,9,10$ and 11$)$, it is evident that the rotational speed of the tool is the important factor that has a large influence on the resultant surface roughness $(\mathrm{Ra})$ of the welded area of the joint and the increase in tool rotary speed decreases the surface roughness (Ra). The values of (Ra) are decreased from $6.8 \mu \mathrm{m}$ with the rotational speed 600 $\mathrm{rpm}$ to $4.8,4.4$, and $4.1 \mu \mathrm{m}$ at the beginning of welding operation for the other used rotational speeds respectively. Also, all the values of (Ra) are decreased with the increase of the rotational speeds throughout the welding distance. This may be due to the increase in material mixing during the welding process and when the tool rotational speed increases, the material mixing becomes better due to an increase in heat input. Therefore, the amount of non-mixed materials decreases, and it causes a reduction in both flash level and surface roughness and respectively the values of ( $\mathrm{Ra}$ ) are becoming less.

In addition, from the comparison between the results at the figures (8,9,10and 11) with the results in Fig.(12), it is clear that the increase in the welding speed leads to an increase in the surface roughness $(\mathrm{Ra})$ and when the welding speed is low, the material mixing is better and fewer defects are seen in the weld area. However, the material mixing is poor when increase the welding speed and causes the formation of circular furrows along with the welding line and the flash level is higher when traverse speed goes beyond $80 \mathrm{~mm} / \mathrm{min}$. This leads to the bad quality of the welded area of the joint.

From the deep analysis of the results, the increase in US power decreases the surface roughness and gives better surface quality, it is may be due to the use of highfrequency vibration, which causes localized heating and leads the materials to be plasticized well. In the same condition, the flow action improves and materials are mixed better and the surface of weld area is relatively smoother and at high power vibration, the amount of flash that damages the surface quality decreases. Therefore, the surface roughness is reduced by an increase in US vibration power. Also, from the analysis, the increase in plunging depth, the amount of material that should be stirred becomes higher. Therefore, at constant heat input, the material mixing is poor and it damages the surface quality of the weld line. It means that, by increasing welding axial force, the surface roughness increases, accordingly.

Therefore, it is obvious that the welding axial force having an important influence on welded area surface quality.

Fig.(13) illustrates the effect of all used parameters [600 $\mathrm{rpm}, 80 \mathrm{~mm} / \mathrm{min}$ and $40 \mu \mathrm{m}, 800 \mathrm{rpm}, 80 \mathrm{~mm} / \mathrm{min}$ and $40 \mu \mathrm{m}, 1000 \mathrm{rpm}, 80 \mathrm{~mm} / \mathrm{min}$ and $40 \mu \mathrm{m}, 1200 \mathrm{rpm}$, $80 \mathrm{~mm} / \mathrm{min}$ and $40 \mu \mathrm{m}$ and $1200 \mathrm{rpm}, 160 \mathrm{~mm} / \mathrm{min}$ and $40 \mu \mathrm{m}]$ on the surface quality of the welded area as described, analyzed and discussed before. 


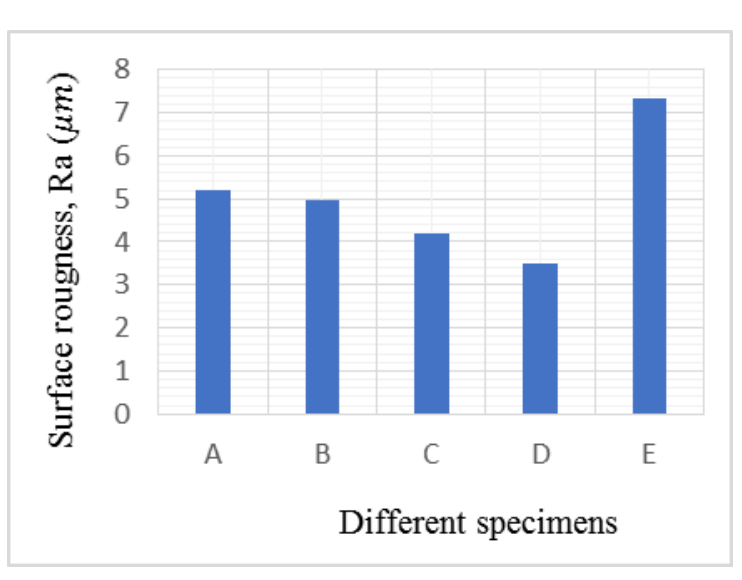

Figs.(13) The average values of the surface roughness for the different specimens.

\section{The conclusions:}

The analysis of the results when using the two methods of welding (UAFSW and CFSW), is relived the following conclusions:

1. The ultimate tensile strength at low and medium welding speeds ( 80 and $120 \mathrm{~mm} / \mathrm{min}$ ) is generally high in both two types of welding, and it is increased by about $16 \%$ in UAFSW than the conventionally (CFSW).

2. A clear decrease in the ultimate tensile strength is shown at high welding speeds (140 and $160 \mathrm{~mm} / \mathrm{min}$ ) especially for conventionally friction stir welded samples.

3. The elongation is increased when ultrasonic vibration is applied and the percentage of increases are 15 and $7 \%$ is obtained at welding speeds of 80 and 120 $\mathrm{mm} / \mathrm{min}$ respectively.

4. The micro-hardness profiles for conventional FSW and ultrasonic-assisted friction stir welding are close in most regions except the stirring zone.

5. The values of micro-hardness are higher in ultrasonicassisted friction stir welding than conventional FSW.

6. The results indicated that the increase of the welding speed to $160 \mathrm{~mm} / \mathrm{min}$, leads to an obvious increase in the surface roughness $(\mathrm{Ra})$.

7. The values of $(\mathrm{Ra})$ are high at the beginning of welding span for all use of the rotational speeds and the welding speeds. But in the middle distance of span, the improvement of the surface quality is clear, and at the end of the welding operation, the values of ( $\mathrm{Ra}$ ) is increased but with small values of roughness as compared with the values at the beginning of welding operation.

8. The rotational speed of the tool is the important factor that has a large influence on the resultant surface roughness $(\mathrm{Ra})$ of the welded area of the joint and the increase in tool rotary speed decreases the surface roughness $(\mathrm{Ra})$.

9. The increase in the welding speed leads to an increase in the surface roughness ( $\mathrm{Ra}$ ) and when the welding speed is low, the material mixing is better and fewer defects are seen in the weld area.

10.The increase in US power decreases the surface roughness and gives better surface quality.

\section{References:}

[1] R. Azlan, R. Izamshah, M. Hadzley, M.S. Kasim, M. Arfauz, M. Akmal," Experimental investigation of surface roughness using ultrasonic-assisted machining of hardened steel ", Proceedings of Mechanical Engineering Research Day, 2016, pp. 212-213, March 2016.

[2] Ramli, Azlan and Raja Abdullah, Raja Izamshah and Abu Bakar, Mohd Hadzley and Kasim, Mohd Shahir and A. Rahman, Muhamad Arfauz and Mohd Zakaria, Muhammad Akmal," Investigation on Improvement of Surface Roughness Using Rotary Ultrasonic Assisted Machining Technique for Hardened Steel Material", Journal of Mechanical Engineering (JMechE), SI 3 (1). pp 118-134, 2017, ISSN 18235514.

[3] Cini Babuji, Dr. N Santhosh Kumar, K Vijayan, G NagamalleswaraRao, Joji J Chaman, "Effect of machining parameters on surface roughness and material removal rate during rotary ultrasonic machining of silicon carbide ", International Research Journal of Engineering and Technology (IRJET), Vol 04 Issue: 06, June -2017.

[4] Xiaofen Liu, Wenhu Wang, Ruisong Jiang, Yifeng Xiong, Kunyang Lin, Junchen Li, "Investigation on surface roughness in axial ultrasonic vibrationassisted milling of in situ TiB2/7050Al MMCs", The International Journal of Advanced Manufacturing Technology, Issue 1-2/2020.

[5] Najib A. Muhammad, ChuanSong Wu, "Evaluation of capabilities of ultrasonic vibration on the surface, electrical and mechanical behaviors of aluminum to copper dissimilar friction stir welds", International Journal of Mechanical Sciences, May 2020. S0020-7403(20)30361-1.

[6] Hong-Xiang, Wang; Chu, Wang; Jun-Liang, Liu; Shi, Gao; Wen-Jie, Zhai," Analysis of Surface and Subsurface Damage Morphology in Rotary Ultrasonic Machining of BK7 Glass ", NASA Astrophysics Data System (ADS), 2017-11-01.

[7] Omolayo M. Ikumapayi, Esther T. Akinlabi," Experimental data on surface roughness and force feedback analysis in friction stir processed AA7075 - T651 aluminum metal composites ", Science Direct, Vol 23, April 2019, 103710 
[8] Rajesh Kumar Bhushan, Deepak Sharma, "Investigation of mechanical properties and surface roughness of friction stir welded AA6061T651", International Journal of Mechanical and Materials Engineering, Vol 15, Article number: 7, 06 June 2020.

[9] P. V. Chandra Sekhara Rao, B. Ramesh Chandra, Aluri Manoj," The study of surface integrity on friction stir welded brass plates", AIP Conference Proceedings; Volume 2269, Issue,10.1063/5.0019656, 2269, 0301072020.

[10] Azlan Ramli, R. R. Abdullah, Muhammad Akmal Mohd Zakaria, "Investigation on Improvement of Surface Roughness Using Rotary Ultrasonic Assisted Machining Technique for Hardened Steel Material", Journal of Mechanical Engineering, Vol. SI 3 (1), pp 119-134, 2017.

[11] Saqib Anwar, Mustafa M. Nasr, Mohammed Alkahtani, Abdul-Aziz Altamimi," Predicting surface roughness and exit chipping size in BK7 glass during rotary ultrasonic machining by adaptive neuro-fuzzy inference system (ANFIS) ", Proceedings of the International Conference on Industrial Engineering and Operations Management Rabat, Morocco, April 11-13, 2017.

[12] Adirek Baisukhan, Wasawat Nakkiew," Sequential Effects of Deep Rolling and Post-Weld Heat Treatment on Surface Integrity of AA7075-T651 Aluminum Alloy Friction Stir Welding ", Materials (Basel), Vol 12(21), 2019 Nov, PMC6862255.

[13] Hongxuan Wang, Jiayi Zhang, Bin Wang, Mingyang Ma, Danqing Yi," Influence of surfaceenhanced treatment on microstructure and fatigue performance of $6005 \mathrm{~A}$ aluminum alloy welded joint", Journal of Manufacturing Processes, 202011-07,

DOI:10.1016/j.jmapro.2020.10.076.

[14] Ahmadnia M, Seidanloo A, Teimouri R, Rostamiyan Y, and Titrashi G. "Determining influence of ultrasonic-assisted friction stir welding parameters on mechanical and tribological properties of AA6061 joints", The International Journal of Advanced Manufacturing Technology, 78(9-12): pp. 2009-2024, 2015.

[15] Liu H, Hu Y, Du S and Zhao H., " Microstructure characterization and mechanism of autoplastic effect in friction stir welding assisted by ultrasonic vibrations on the bottom surface of workpieces", Journal of Manufacturing Processes, Vol 42, pp 159-166, 2019.

[16] Masoud Ahmadnia, Amin Seidanloo, Reza Teimouri, Yaser Rostamiyan, Khadijeh Ghasemi Titrashi," Determining the influence of ultrasonicassisted friction stir welding parameters on mechanical and tribological properties of AA6061 joints ", Int J Adv. Manuf Technol, Vol 78,pp2009-2024, 2015.

[17] Ankit Sharma, Atul Babbar, Vivek Jain, Dhiraj Gupta, "Enhancement of surface roughness for brittle material during rotary ultrasonic machining", ICMMM 2018, MATEC Web of Conferences 249, 0100,2018

[18] M A Constantin, E L Nitu, DM Iordache, C Badulescu," Study on the influence of technological parameters on the friction stir butt welding process of pure copper plates ", IOP Conf. Series: Materials Science and Engineering,968,2020.

[19] Jatinder Kumar, J. S. KhambaII, "An experimental study on ultrasonic machining of pure titanium using designed experiments "Journal of the Brazilian Society of Mechanical Sciences and Engineering, Vol.30 no.3 Rio de Janeiro July/Sept. 2008.

[20] M. Merklein and H. Hagenah," Investigation of Vibration Assisted Friction Stir Welding "Engineering Materials, Vols. (504-506), pp 741746, 2012.

[21] Gianluca D'Urso, Michela Longo, Claudio Giardini, Elisabetta Ceretti, " Quality Analysis of Friction Stir Welded Butt Joints using Experiments and Simulations ", Engineering Materials, Vols. (504-506), pp 759-764, 2012.

[22] S. Yu. Tarasov, V. Ye. Rubtsov, E. A. Kolubaev, A. N. Ivanov, S. V. Fortuna1, and A. A. Eliseev," Ultrasonic-assisted friction stir welding on V95AT1 (7075) aluminum alloy", AIP Conference Proceedings, Volume 1683, Issue, 10.1063/1.4932921, Published Online: 27 October 2015.

[23] Mohamadreza Nourani, Abbas S. Milani, Spiro Yannacopoulos, "Taguchi Optimization of Process Parameters in Friction Stir Welding of 6061 Aluminum Alloy: A Review and Case Study", J of Scientific Research, Vol.3 No.2, February 2011.

[24] Mishra R, Jain S, "Friction stir welding (FSW) process on aluminum alloy 6082-T6 using Taguchi"s". International Journal of Research in Engineering and Innovation (IJREI) 2019. DOI:10.36037/ijrei.2019.

[25] Rostamiyan Y, Seidanloo A, Sohrabpoor H, Teimouri R., "Experimental studies on ultrasonically assisted friction stir spot welding of AA6061", Archives of civil and mechanical engineering, 15(2): pp 335-346, 2015.

[26] Kundu J and Singh H., "Modelling and analysis of process parameters in friction stir welding of AA5083-H321 using response surface methodology", Advances in Materials and Processing Technologies, 4(2), pp 183-199, 2018. 
[27] Kundu J, Ghana's G, Rattan N, and Sharma S., "Effect of different parameters on heat generation and tensile strength of FSW AA5083 joint", International Journal of Current Engineering and Technology, Vol.7, No.3 pp 1170-1174, June 2017.

[28] Jamaican H, Farahani M, Givi K, and Vafaei M., "Study on the effects of friction stir welding process parameters on the microstructure and mechanical properties of 5086-H34 aluminum welded joints", The International Journal of Advanced Manufacturing Technology, 83(1-4): pp 611-621, 2016.

[29] C.B. Jagadeesha," Analysis and design of friction stir welding tool", J Mech Behav Mater, 25(5-6), pp 179-182, 2016.

[30] Osama M. Mabrouk, "Friction stir welding assisted by ultrasonic vibration", Master thesis, Menoufiya University, Egypt, 202 